\title{
Co-designing services with vulnerable consumers
}

\section{Introduction}

Reducing alcohol consumption among adolescents is one of the foremost challenges for society given evidence that higher-level alcohol consumption continues into adulthood and may have significant physical, mental and social consequences (McCambridge et al., 2011). Adolescents have been shown to be particularly vulnerable to alcohol advertising and messages (Siqueira et al., 2015) owing to rapid changes in their brain development (Randolph et al., 2013). Services, particularly alcohol education, are important to challenge and counteract the positive messages surrounding alcohol consumption in society (McBride et al., 2004; Szmigin et al., 2011; Rundle-Thiele et al., 2013). There remains scope to improve alcohol education as effectiveness of programs varies (Foxcroft and Tsertsvadze, 2012a; Onrust et al., 2016). Transformative service research (TSR), which aims to improve the wellbeing of consumers and communities through service (Ostrom et al., 2010), offers an avenue for achieving this goal. Although all services have the potential to be transformative in that they have the capacity to improve consumer wellbeing, some services such as education and health services explicitly aim to do so and are of particular interest in TSR (Anderson et al., 2013; Guo et al., 2013; Rosenbaum et al., 2011).

The majority of school-based alcohol education tends to be expert-driven in design, with little or no involvement of the primary service beneficiaries - adolescents (Dietrich et al., 2016). Such a topdown design approach has been criticized as it does not consider the specific needs and requirements of service users (Lundkvist and Yakhlef, 2004; Witell et al., 2011), nor recognize that users actively co-create service experiences (McColl-Kennedy et al., 2012; Osei-Frimpong et al., 2015). Active involvement of users in design and development processes addresses this criticism (Edvardsson et al., 2012; Steen et al., 2011). While user involvement in service innovation is gaining acceptance, the practice remains in its infancy (Hoyer et al., 2010; Gemser and Perks, 2015). Edvardsson et al. (2013) note that conventional market research techniques such as interviews, surveys and focus groups remain the dominant means of consumer insight generation for the design process. The slower than expected move toward more active methods of user involvement may be attributable to time and cost intensive processes needed to identify qualified users who are willing and able to contribute to innovative ideas that address the needs of the broader marketplace (e.g. Piller and Walcher, 2006; Poetz and Schreier, 2012).

One specific form of active user involvement is co-design, an approach that facilitates a collaborative design process between designers and users with the aim to involve users as "experts of their experiences” (Sanders and Stappers, 2008, p.6). Steen et al. (2011, p.53) propose that co-design is essentially about "helping the users to articulate...precisely and realistically which benefits to aim for and to match these benefits to the goals of a service design project". In this way, service users can 
provide insights into their needs and contribute to new ideas that transcend information sourced from traditional market research techniques (Lundkvist and Yakhlef, 2004; Witell et al., 2011) and expert views dominating contemporary practice (Holmlid, 2009; Krippendorff, 2006). Yet, limited research is available that examines how users can be involved in co-design or how their involvement might affect design outcomes. This has led to the recent call for exploration of new approaches to service design, with a focus on investigating participatory or co-design processes, to enhance service user experience and reduce the chances of costly new service failures (Ostrom et al., 2015). In particular, “designing services for vulnerable consumers" has been identified as a key priority to advance and benefit the service field (Ostrom et al., 2015, p.140). Hence, additional research in co-design is needed in new areas of application such as transformative design (Sangiorgi and Junginger, 2015). This research contributes to addressing these calls by investigating how vulnerable consumers can be involved in transformative service design and how this approach may enhance the design of such services. More specifically, we pose the following research question: "How can vulnerable consumers be involved in transformative service design?”

This research contributes to knowledge in TSR - a priority in service research (Anderson et al., 2013; Wunderlich et al., 2013) - and service design by extending the boundaries of our understanding of processes and tools for the involvement of vulnerable consumers in transformative service design as called for by the literature (Ostrom et al., 2015). The research examines and reports on the involvement of vulnerable consumers in the design process of a specific transformative service - an alcohol education program targeted at adolescents. By engaging in a co-design process with vulnerable consumers, researchers were able to articulate theoretically and practically how co-design with vulnerable consumers differs from existing user involvement processes. As a result, a six-step co-design framework is proposed including: resourcing, planning, recruiting, sensitizing, facilitation, and evaluation of outcomes. For practice, the framework outlines how co-design might be applied so that vulnerable consumers can become empowered participants during the service design process. Overall, this study contributes to the contemporary topic of addressing "societal concerns and value in the service environment" by examining co-design as a possible approach to enhance "mindful service experiences that are beneficial to the recipients, to those around them, as well as to the environment" (Ranaweera and Sigala, 2015, p.6).

\section{Literature review}

\section{Transformative service research}

Enhancing the wellbeing of vulnerable consumers through service design, provision and outcomes has been identified as a core focus for TSR (Rosenbaum, 2015). Vulnerable consumers are those whose individual characteristics (e.g. age) or individual states (e.g. cognitive or physical capacity) interact with external conditions (the environment) to create a state of powerlessness in consumption situations 
(Baker et al., 2005). From this perspective, consumer vulnerability is contextual and can be transient. For example, in the case of adolescents, their still-developing cognitive capacity (Piaget, 1952) interacts with the prevalence of alcohol advertising (Siqueira et al., 2015) and the pervasiveness of "a culture of intoxication" (Fry, 2010) to create a state of powerlessness in alcohol consumption situations resulting in the average age of initiation being just over 15 years (AIHW, 2014). Vulnerable consumers may have difficulty defining their goals and preferences while simultaneously possessing fewer resources to achieve those goals and preferences (Ringold, 2005). Previous studies in TSR have examined vulnerable consumers' adoption of transformative services (Schuster et al., 2013, 2015) and service outcomes in these populations (Rosenbaum et al., 2014; Rosenbaum et al., 2011).

Despite the call for research to investigate the design of services for vulnerable consumers in TSR, little research has focused on understanding how vulnerable consumers can be involved in and contribute to service design. This may be attributable, at least in part, to the fact that vulnerable consumers are generally treated in the way that well-meaning others think they should be treated (Baker et al., 2005), perhaps contributing to the dominance of expert-driven transformative services, such as alcohol education, where researchers and practitioners often design services they think should benefit vulnerable consumers. Donetto et al. (2015, p. 241) highlight the difficulty of "equality, equal contribution and mutual respect" in healthcare contexts, where "traditional roles of provider and recipient of care are clearly demarcated". The benefits of an inclusive approach to transformative service design are highlighted in the study by Engström and Elg (2015), which shows an improved sense of relatedness for lung cancer patients as a result of participation in service design. Corus and Saatcioglu (2015) propose an intersectionality conceptual framework for designing services for consumer groups with multiplicative vulnerabilities (e.g. age and race). While the framework is operationalized at a strategic level, which outlines broad principles for fostering inclusion, it does not provide insights at a tactical level, which outlines practically how vulnerable consumers can be included in service design as is the aim of this study.

\section{Service design}

Service design can be best understood as a creative, human-centered and iterative approach to service innovation (Wetter-Edman et al., 2014), and can be defined as a “... systems challenge driven by an understanding of human experience" (Evenson, 2008, p.26). Two concepts underpin service design. First, as a systems challenge, service design concerns the design of service systems, which are value co-creation configurations of people, technologies and additional resources that interact with other service systems to co-create value (Maglio and Spohrer, 2008). The challenge is to design service systems that support value co-creation and resource integration among multiple actors (Pinho et al., 2014). Second, service design takes a human-centered design approach, as it follows an "outside-in perspective" to investigate and understand how consumers experience a service (Holmlid, 2007; 
Holmlid and Evenson, 2008). Human-centered design aligns with the phenomenological value perspective of S-D logic (Vargo and Lusch, 2008), which proposes that design has no significant meaning unless it becomes part of the living experience of people and sustains them in the performance of their own actions and experiences (Krippendorff, 2006). The design of a service thus starts with an understanding of users' experiences, value co-creation activities and interactions, and the subsequent service system design in the form of a supporting configuration of resources (i.e. value proposition) for users to integrate and operate on (Edvardsson et al., 2012; Patrício et al., 2011).

Service design has also been investigated for its transformative role (Sangiorgi, 2011). In this context, “design for service” was introduced, suggesting services not as design objects but as means to support the emergence of a more collaborative, sustainable and creative society and economy (Kimbell, 2011; Meroni and Sangiorgi, 2011). This approach required changes to the traditional model of service production and delivery, which are also fundamental to S-D logic: from the focus on discrete transactions of outputs and the definition of users as passive recipients of value, towards defining users as active participants in the creation of wellbeing and value (Bentley and Wilsdon, 2003; Cornwall, 2008). This shift has led to a focus on exploring collaborative service models including co-creation with service users (Cottam and Leadbeater, 2004; Mele et al., 2014).

\section{User involvement and co-design}

Collaboration with users during design processes is considered vital as users possess specific needs and problems and thus can contribute valuable knowledge to addressing these needs and problems (Holmlid, 2009). This position draws on the participatory design theory principle that "it is possible to gain access to the experiencer's world only through his or her participation in expressing that experience” (Sanders and Dandavate, 1999, p. 90). As design theory has evolved toward humancentered design, Krippendorff (2011, p. 413) even suggests that "users often are better designers of their own worlds than professionals", implying that "the point of professional design lies not in insisting on being experts but in enabling others to design their own world”. The importance of user involvement is also acknowledged in innovation and new service development research (Alam, 2002; Hoyer et al., 2010). Studies show that user-generated ideas can increase user benefits (Kristensson et al., 2004; Magnusson et al., 2003), be highly innovative (Magnusson, 2009; Poetz and Schreier, 2012) and enhance consumers' perceptions of a firm's ability to innovate (Schreier et al., 2012). It should be noted that these studies focus on involving users who have the willingness and capabilities to contribute to innovation activities such as 'lead users', ‘emergent consumers’ or ‘market mavens' (von Hippel 2001; Piller and Walcher, 2006; Hoyer et al., 2010). This is, however, problematic in transformative service design for vulnerable consumers who may not have the willingness or capabilities to take part in innovation activities. 
Co-design focuses on those who are directly affected by a design (Mattelmäki and Visser, 2011). Users are 'co-designers', meaning that designers and participants not trained in design collaborate throughout the whole span of a design process with the aim of achieving collective creativity (Sanders and Stappers, 2008). A core principle of co-design is that the involved users or other stakeholders are empowered to contribute to the design process and that their experience and expertise is valued (Mattelmäki, 2008). In fact, Mattelmäki and Visser (2011) suggest that key to participatory design approaches is empowerment, which means that the ones who are affected by the design should also have an opportunity to influence it. This proposition is key to this research as it supports Baker et al.'s (2005) argument that consumer empowerment is vital in both market and policy responses to consumer vulnerability.

User involvement predominantly concerns users taking over innovation or design activities traditionally executed by the firm (Fuchs and Schreier, 2011). Thereby firms 'democratize' innovation by equipping users with appropriate toolkits to allow them to independently undertake needs-related innovation activities (von Hippel, 2001; 2005; Franke et al., 2006; Boudreau and Lakhani, 2013). In contrast, the purpose of co-design is to facilitate the "exchange between people who experience products, interfaces, systems and spaces and people who design for experiencing” (Sanders and Dandavate, 1999, p. 90). In order to facilitate this exchange, considerations across the design space (Sanders and Westerlund, 2011), design process planning and facilitation (Visser et al., 2005; Donetto et al., 2015), the roles taken by designers (Manzini and Rizzo, 2011; Mattelmäki and Visser, 2011), and applied design tools and methods (Sanders et al., 2010) are required. For example, both Visser et al. (2005) and Steen et al. (2011) emphasize the importance of the planning and preparation phase which includes the formulation of design goals, the selection of participants as well as the sensitizing of users in order to increase their familiarity with the underlying design task. Similarly, Donetto et al. (2015) suggest that extensive preparation time is required prior the actual co-design event, specifically in terms of gathering user insights and experiences through observational fieldwork.

During the actual co-design process, Manzini and Rizzo (2011) propose that designers need to change their roles in order to encourage user participation during the co-design process and to trigger ongoing design initiatives beyond the actual design process. Design tools are a key aspect of empowering users and facilitating collaboration during the co-design process (Mattelmäki and Visser, 2011). Forms of facilitation can involve 'giving voice' to users by providing them with appropriate design tools or designers actively participating as co-designers during the process (Mattelmäki and Visser, 2011). Such design tools - also described as “tools for conversation” - are essentially built upon a collaboration-based mindset and aim to facilitate conversation about the given design content (Mattelmäki and Visser, 2011). In their application, design tools can be very diverse, ranging from simple and traditional communication tools (e.g. posters, slideshows) to more sophisticated and original ones (e.g. videos, possibility cards, interactive media, competitions). For example, Brandt et al. (2008) 
used board game-style rules, involving a game board, playing cards and turn-taking, to encourage collaboration, co-discovery and the creation of new and shared design representations amongst participants. Mattelmäki (2008) proposes design probes as a method that allows users to reflect on and communicate their experiences. This method can thus be effective not only for collecting user data but also to encourage collaborative exploration amongst co-design participants. Clatworthy (2011) shows that cards can assist cross-functional teams in innovation and can also assist to build team cohesiveness during the first phases of the new service development process. The card sorting activity is a method that has been widely employed in different research contexts such as psychology and psychiatry (Pazart et al., 2011), knowledge and software engineering (Palmer et al., 1988) as well as website optimization (Upchurch et al., 2001). In these contexts the card sorting method has been suggested as a useful elicitation tool for a number of outcomes, such as testing users' recall knowledge, distinguishing between likes and dislikes, and providing insight and input for further analysis. It can achieve these outcomes while still providing a flexible, easy to administer tool for researchers, which is simple for participants to engage with (Nurmuliani et al., 2004; Upchurch et al., 2001; Zimmerman and Akerelrea, 2002). The present study extends on these studies by investigating the application of the card sorting activity as a possible tool to empower and engage vulnerable consumers in the co-design process.

Despite the emerging literature investigating co-design, including its approach and the development and application of suitable design tools, knowledge within this field is still nascent. Following from the examination of the co-design literature, it is apparent that there is currently no comprehensive framework available that specifies how vulnerable consumers might be involved as active and empowered participants during the service design process (cf. Ostrom et al., 2015). In their review of the concepts of co-design and co-creation from a design research perspective, Mattelmäki and Visser (2011), and more recently Donetto et al. (2015), concluded that co-design can be approached differently in terms of the time span of the engagement and the phases of its process. In addition, the innovation and new service development literature provides generic frameworks for active user involvement although the focus is primarily on innovative users (Hoyer et al., 2010) or business-tobusiness customers (Alam, 2002). These frameworks do not accommodate the unique characteristics of vulnerable consumer groups that may influence the efficacy of such processes. Vulnerable consumer groups are often marginalized by society and may experience a sense of powerlessness (Baker et al., 2005) that reduces their motivation to contribute to co-design activities. In addition, inherent individual characteristics that underpin consumer vulnerability (e.g. age and cognitive capacity) may further impact their ability to contribute to co-design. Previous research supports the proposition that not all consumers possess equal capacity to contribute to co-design (e.g. Donetto et al., 2015; Engström and Elg, 2015). This highlights the need for research that examines specifically the co-design process for vulnerable consumer groups, and identifies the differences with existing user involvement processes. 


\section{Method}

\section{Context and structure of field study}

School-based alcohol education is a particularly fruitful context for exploring and analyzing the process for including vulnerable consumers in service design. Although school-based alcohol education programs aim to enhance adolescents' wellbeing, through knowledge transfer and subsequent creation of opportunity or ability to reject or modify alcohol consumption behaviors, these services also have the potential to negatively affect adolescents' identity, particularly if they are already drinking alcohol. This possibility, together with adolescents' inherent vulnerability given their age (i.e. brain development) (Siqueira et al. 2015), make it particularly important that they are involved in the service design process. Further, this context is also interesting from the perspective of co-design, as health service exchanges are known for barriers to consumer-provider collaboration, such as power distance (Berry and Bendapudi, 2007; Donetto et al., 2015).

A case study approach (Merriam, 1998) was employed, with six high schools in Australia identified as sites to conduct co-design sessions for a school-based alcohol education program. This case study approach allows a) the phenomenon to be studied in its natural setting, b) the research question to be answered in a way that acknowledges the complexity and dynamic nature of the phenomenon studied, and c) an exploratory investigation of a phenomenon that is not well understood (Voss et al., 2002). The present research followed a literal replication logic thus selecting cases that predict similar results (Voss et al., 2002). The schools were sourced from a larger cluster randomized controlled trial of a school-based alcohol education program named GOKA (Rundle-Thiele et al., 2013; 2015). GOKA is an expert-designed program and features interactive lessons using online games and practical activities to enhance adolescents' learning experiences whilst reducing positive attitudes and intentions towards binge drinking (Rundle-Thiele et al., 2013; 2015). The GOKA program was delivered in 14 schools and lasted for a full-day (six modules) at each school. The participation in this one-day program was voluntary for all adolescents. More details of GOKA are available in (Rundle-Thiele et al., 2013; 2015).

One to 14 weeks after the delivery of the full-day GOKA program, co-design sessions involving 58 adolescents were facilitated. Different to the full-day program, the co-design sessions were conducted with a maximum of ten participants. Groups of more than five members can be beneficial for creating a group feeling and encouraging group discussions, but keeping groups small is also important to be able to pay attention to every individual (Visser et al., 2005). All co-design sessions took place at the respective schools in different rooms, including a boardroom, meeting rooms or class rooms. The co-design sessions were tape-recorded and transcribed. In addition, field notes were taken by the principal researcher after the co-design facilitation. The collected data were analyzed using NVivo Version 10 and data were coded using thematic analysis, where the researchers allowed themes to emerge from the data (Thomas, 2006). 


\section{GOKA program delivery and user sensitizing}

The full-day program consisted of six lessons featuring online games and practical activities. Adolescents were asked to provide feedback in regards to the design, content and usefulness of the individual games and activities through online surveys. Service users' mean age was 14.7 years with $54 \%$ being male. The GOKA program was designed to be highly interactive and adolescent-oriented through the online gaming components and practical activities, such as wearing beer goggles, "passing out” and a "stork balance" activity.

The full-day GOKA program "sensitized" the users to the topic prior to the co-design sessions. The basic principle of sensitizing is to let people express and reflect on memories, opinions, dreams, and past experiences around a specific topic and, as such, it increases their familiarity with the topic (Visser et al., 2005). In the current study adolescents were engaged in, and reflected on through a survey, the existing GOKA program and its individual activities for an entire school day. In addition, as the lead researcher was involved in delivering the GOKA program and the subsequent co-design sessions the sensitizing stage also created an opportunity to build familiarity and trust between the facilitator and potential co-design participants.

\section{Recruitment for the co-design session}

The recruitment of adolescents for the co-design sessions was conducted by $10^{\text {th }}$ grade (14-16 yearold adolescents) coordinators, pastoral care coordinators, as well as health and physical education teachers. These contacts were established through the GOKA program delivery and allowed for a more streamlined recruitment process. Participation in the co-design sessions was voluntary. All participants had been involved in the GOKA program prior to the co-design sessions and thus were familiar with the program content and facilitator. From the sample of 60 participants (i.e. 10 adolescents per codesign session), 58 adolescents arrived to the scheduled co-design sessions and participated in the entire session.

The co-design sessions were restricted to a timeframe of 60 minutes to ensure that participants did not become fatigued. Sixty-minute sessions have been found to be ideal in length when working with vulnerable groups (Vaughn et al., 1996). To maximize active participation the facilitator aimed for a private setting. In all sessions the facilitator emphasized privacy and confidentiality for participants in order to allow them to express their creativity and share openly their thoughts and feelings about sensitive, alcohol-related materials.

Steen et al. (2011, p.53) stress the importance of articulating "precisely and realistically which specific benefits [co-design sessions] aim to achieve”. The facilitator invited and briefed the participants on two key dimensions. First, the participants were asked to reflect on their experiences with the GOKA program in which they had previously participated and second, they were invited to help create a more user-centered version of GOKA. The facilitator emphasized that both negative and positive comments 
were welcomed and expected. The facilitator also took care to encourage quiet participants to voice their opinions by directing specific questions to them. The final collage drawing activity allowed participants that were less outspoken in the discussion to write and reflect through a different medium.

\section{Findings}

\section{Application of co-design tools}

To empower the participants to review the individual alcohol education program activities and to develop their own preferred programs within the timeframe of 60 minutes a card sorting activity was employed. To evaluate the usefulness of the card sorting activity for co-design with vulnerable participants we applied the framework suggested by Sanders et al. (2010). Their framework (Table 1) specifies participatory design tools and techniques that can be employed to engage non-designers in collaborative activities (e.g. making, telling and/or enacting) and/or for a particular purpose (e.g. for probing participants, for priming participants, to get a better understanding of their current experience or to generate new ideas or design concepts). 
Table 1 - Tools and techniques used in co-design

\begin{tabular}{|l|c|c|c|c|}
\hline Tools/Techniques & Probe & Prime & Understand & Generate \\
\hline Telling (Cards) & \multicolumn{1}{|c|}{$\checkmark$} & $\checkmark$ & \\
\hline $\begin{array}{l}\text { Rate and discuss existing } \\
\text { GOKA games and } \\
\text { activities. }\end{array}$ & $\checkmark$ & \multicolumn{1}{|c|}{} & \\
\hline $\begin{array}{l}\text { Rate and discuss a range } \\
\text { or other potential games } \\
\text { and activities that were } \\
\text { not part of GOKA } \\
\text { (included nine games } \\
\text { and activities). }\end{array}$ & $\checkmark$ & $\checkmark$ & $\checkmark$ & \\
\hline $\begin{array}{l}\text { Making (2-D collages) } \\
\text { Suggest new games and } \\
\text { activities or improve } \\
\text { existing ones. }\end{array}$ & & & & \\
\hline Enacting (2-D collages) & & & & \\
\hline $\begin{array}{l}\text { Adolescents create their } \\
\text { own unique alcohol } \\
\text { education program. }\end{array}$ & & & & \\
\hline
\end{tabular}

Source: Adapted from Sanders et al., (2010) 
The card sorting activity was found to be useful for engaging the participants in "telling" and "making” as well as "enacting” (see Table 1). In particular, the cards were beneficial for rating and discussing the individual activities in a playful way (i.e. telling). We additionally used blank cards, which allowed participants to provide suggestions to improve existing activities and/or develop new games and practical activities (i.e. making). Finally, participants could use selected cards and assemble 2-D collages, hence developing their own unique alcohol education program (i.e. enacting).

We also examined the card sorting method in their capabilities to assist in "probing” and "priming”. Probing participants means developing a conversation between users and the design researcher to gain a better understanding of a context of use and to help spark new design ideas (Mattelmäki, 2008). Priming participants means immersing participants into the topic with the aim to encourage and motivate them to contribute (Sanders et al., 2010). These capabilities were indicated during the card sorting activity. The use of blank cards and the development of 2-D collages also enabled "understanding" and "generating” as these activities provided a better understanding of the participants' perceptions of the current alcohol education components and allowed them to generate new ideas for activities and program content.

\section{Co-design facilitation}

The first stage of the co-design sessions focused on the games and activities that were part of the one-day GOKA program (see Table 2). We deliberately chose to begin the co-design sessions with the previously experienced games and activities to develop familiarity, encourage discussion and build confidence among the participants. In accordance with the card sorting method the games and activities were summarized on laminated cards printed approximately A8 card-sized format (see Figure 1 for an example). All adolescents were instructed to individually assess each of the activities and remember where and how they took place before sorting activities into three distinct piles: "likes”, "dislikes" as well as an "unsure" category. 
Table 2 -Activity description

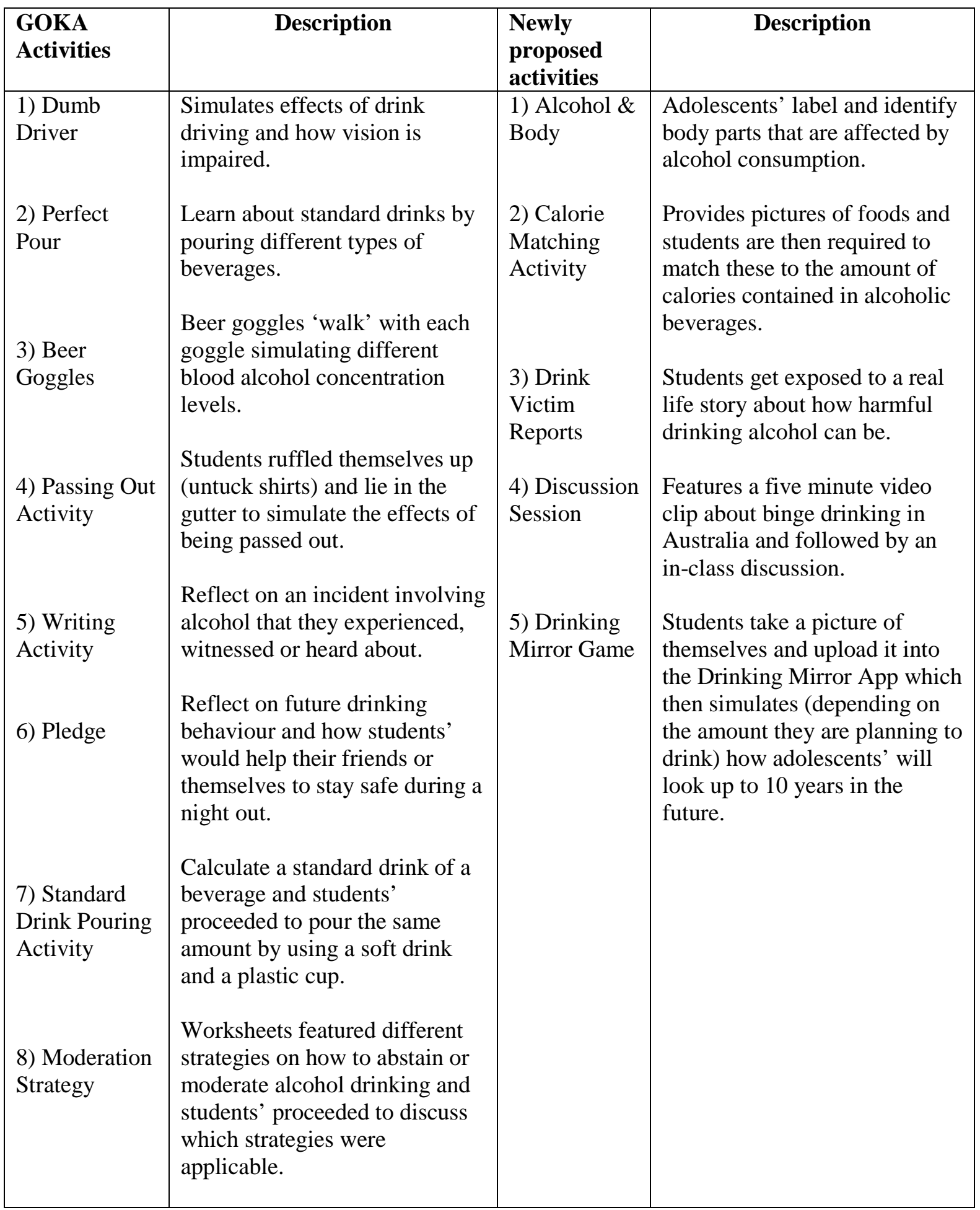


Figure 1 - Example of two cards used in card sorting activity
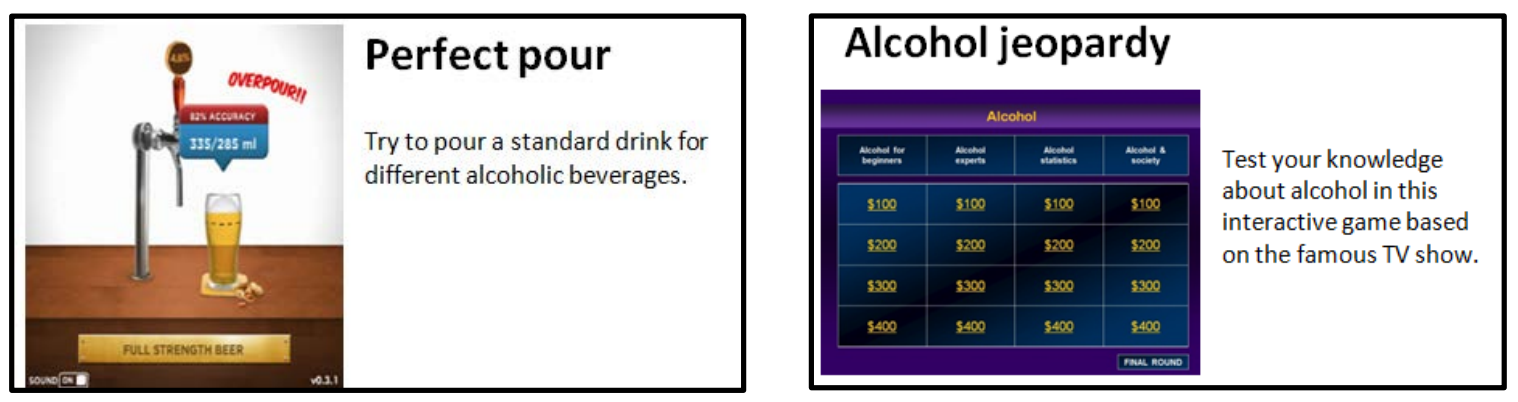

After this individual assessment the researcher selected one of the activities and invited each adolescent to share their reasoning of why they had placed it into either the like or dislike category. A number of probing questions were used to gain deeper insights regarding the adolescents' preferences and perceptions of the games and activities that were part of the current GOKA program. This warmup exercise led to discussions and debates among adolescents in regards to their preferences and beliefs about the specific games and activities they experienced during the one-day program.

After completing the warm-up exercise, cards were distributed that represented games and activities that were not part of the GOKA program (see Table 2), sourced from previous alcohol education programs (e.g. Alcolado and Alcolado, 2011; Hardoff et al., 2013; Will and Sabo, 2010). These activities were novel to the adolescents and once again the researcher gave them time to carefully review each card and then instructed them to follow the same classification procedure that was utilized for the first set of cards. The researcher then went through the activities and invited each adolescent to once again share the reasoning behind their assessment and aimed to gain deeper and more meaningful insights with regards to individual activities. The aim of this exercise was to foster creativity and to provide the participants with a broader background understanding of the topic and design objective in question (Steen et al., 2011).

During the final stage of the co-design session participants were given a set of blank cards in the same size and format as the previous activity cards. The researcher provided two guidelines for adolescents to stimulate output: adolescents were invited to either improve any of the existing GOKA and newly proposed activities and games and/or to develop (sketch/map out) an idea/activity/game of their own. As part of this exercise participants were also asked to propose their own alcohol education program by using any of the available games and activities, including their own suggestions providing they had created some. A photograph was taken of each participant's co-designed program (see Figure 2). 


\section{Figure 2 - An adolescent's designed program}

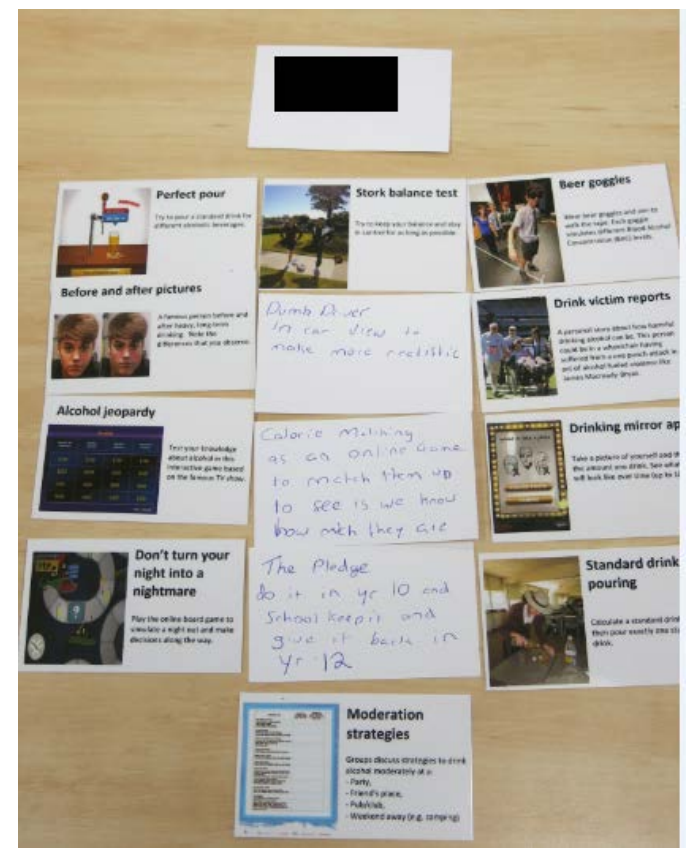

We found that the 2-D collages were particularly useful for engaging more quiet participants that were then able to express their preferences in this individual activity. Whilst the card sorting activity presented an innovative method of fostering creativity and reflection, we also identified room for improvement. For example, the facilitator realized that some participants struggled to capture all their ideas on the blank cards, which suggested that the cards were too small in size. The 2D collage activity could also have presented participants with larger blank cards, butcher paper, post it notes, stickers and colored pens to more creatively express their design. With regards to the activity cards that featured existing GOKA program and evidence-based program activities, some users reported difficulty remembering activities or were confused by the short description. Larger cards with more a better visual representation of the activity and more detailed text may be able to prevent this confusion. Yet, initially introducing participants to cards that showcased familiar activities worked well, as it helped adolescents reflect on the day they took part in and provided a warm up exercise that assisted the creative process rather than starting with unknown activity cards or a blank canvas.

\section{Co-design outcomes}

Following from the co-design facilitation, we were interested in how the participants perceived the individual alcohol education program activities, what specific suggestions for improvements were made by them, and whether these were feasible with regards to their implementation. Table 3 lists eight GOKA activities and describes the activities that were improved by the participants during the co-design sessions. The improvements were based on the users reflecting on personal experiences with the current 
alcohol education program activities as well as discussing five newly-introduced activities that they had not previously been exposed to. The latter is featured in Table 4. Both tables contain information on feasibility as well as user quotes. 
Table 3 - GOKA activities

\begin{tabular}{|c|c|c|c|c|}
\hline Activity & Perceptions & Improvements & Feasibility & Quotes \\
\hline $\begin{array}{l}\text { Perfect } \\
\text { Pour }\end{array}$ & $\begin{array}{l}\text { Engagement, competition, fun } \\
\text { and an element of surprise with } \\
\text { regards how easy it was to over } \\
\text { pour a drink encouraged } \\
\text { multiple game plays. }\end{array}$ & $\begin{array}{l}\text { Combination of the Perfect Pour } \\
\text { game with the Standard Drink } \\
\text { Pouring Activity. }\end{array}$ & $\begin{array}{l}\text { Combining Perfect Pour and } \\
\text { Standard Drink Pouring is feasible } \\
\text { and likely to produce a more } \\
\text { concise, engaging and interactive } \\
\text { component of the program. }\end{array}$ & $\begin{array}{l}\text { M, 15: You can do it like a memory } \\
\text { test as if you played a perfect pour } \\
\text { game first and then you have different } \\
\text { bottles with what drinks were in the } \\
\text { game and then you got to pour so } \\
\text { much in a cup. }\end{array}$ \\
\hline $\begin{array}{l}\text { Beer } \\
\text { Goggles }\end{array}$ & $\begin{array}{l}\text { Challenging real-world } \\
\text { experience that was fun and } \\
\text { engaging. }\end{array}$ & $\begin{array}{l}\text { Ideas that make the activity more } \\
\text { challenging (e.g. obstacle } \\
\text { course) and provide a more } \\
\text { realistic experience (cones, } \\
\text { picking up keys). }\end{array}$ & $\begin{array}{l}\text { Suggested features can be } \\
\text { implemented without the } \\
\text { requirement of monetary } \\
\text { resources. Additional time needs to } \\
\text { be allocated to this activity. }\end{array}$ & $\begin{array}{l}\text { M, 15: Add something ... and put it } \\
\text { into a situation that makes it feel more } \\
\text { real... tie your leg to someone else's } \\
\text { and then you got to try to get through } \\
\text { the obstacle course... }\end{array}$ \\
\hline $\begin{array}{l}\text { Writing } \\
\text { Activity }\end{array}$ & $\begin{array}{l}\text { This activity was boring and } \\
\text { unengaging for most. Only } \\
\text { students that had a story to } \\
\text { share enjoyed this activity. }\end{array}$ & $\begin{array}{l}\text { Limited amount of suggestions } \\
\text { (e.g. read out most interesting } \\
\text { stories in front of class). }\end{array}$ & $\begin{array}{l}\text { More time consuming and } \\
\text { additional screening of stories } \\
\text { required. May sacrifice } \\
\text { authenticity of stories and potential } \\
\text { stigmatisation issues. }\end{array}$ & $\begin{array}{l}\mathrm{M}, 15: \text {...if you were to read it out } \\
\text { then that would make people think } \\
\text { more about drinking alcohol. }\end{array}$ \\
\hline
\end{tabular}




\begin{tabular}{|l|l|l|l|l|}
\hline Pledge & $\begin{array}{l}\text { Split opinions ranging from } \\
\text { pointless to it being a good } \\
\text { reflection task as well as a } \\
\text { meaningful experience with a } \\
\text { good goal setting exercise. }\end{array}$ & $\begin{array}{l}\text { Reduce size of pledges so that } \\
\text { they could fit into a wallet. } \\
\text { School staff collects filled-out } \\
\text { pledges and returns them at } \\
\text { graduation or end of term. }\end{array}$ & $\begin{array}{l}\text { A pocket card sized pledge and } \\
\text { teachers collecting pledges and } \\
\text { returning them at key decision } \\
\text { points (e.g. end of school term/ } \\
\text { before holiday) is feasible. }\end{array}$ & $\begin{array}{l}\text { M, 14: ...if it's a teacher you're } \\
\text { interaction with them stops essentially } \\
\text { at 3 o'clock and you don't have parties } \\
\text { from 8.30 to 3.00. }\end{array}$ \\
\hline $\begin{array}{l}\text { Standard } \\
\text { Drink }\end{array}$ & $\begin{array}{l}\text { Mathematical component was } \\
\text { mostly perceived as a boring } \\
\text { Activity }\end{array}$ & $\begin{array}{l}\text { Pouring standard drinks } \\
\text { immediately after playing the } \\
\text { described as engaging, } \\
\text { entertaining and fun. }\end{array}$ & $\begin{array}{l}\text { Combining Perfect Pour and } \\
\text { Standard Drink Pouring is feasible } \\
\text { and likely to produce a more } \\
\text { concise, engaging and interactive } \\
\text { component of the program. }\end{array}$ & $\begin{array}{l}\text { M, 15: ...do it like a memory test as if } \\
\text { you played perfect pour first and then } \\
\text { you have different bottles with what } \\
\text { drinks were in the game and then you } \\
\text { got to pour so much in a cup. }\end{array}$ \\
\hline $\begin{array}{l}\text { Mode- } \\
\text { ration } \\
\text { Strategy }\end{array}$ & $\begin{array}{l}\text { Too lengthy, boring, confusing } \\
\text { and some students did not even } \\
\text { rement Pour game, featuring the } \\
\text { rember it. }\end{array}$ & $\begin{array}{l}\text { Increase interactivity, reduce } \\
\text { amount of strategies, and allow } \\
\text { more time and space for } \\
\text { discussion in smaller and more } \\
\text { trusting environments. }\end{array}$ & $\begin{array}{l}\text { Back to the design board before a } \\
\text { second-round co-design session. }\end{array}$ & $\begin{array}{l}\text { M, 15: ... It could be more interactive. } \\
\text { Maybe if someone up the front was } \\
\text { going through it...and we were all } \\
\text { talking about it...[make it] a bit more } \\
\text { fun. }\end{array}$ \\
\hline
\end{tabular}


Table 4 - Additionally proposed activities

\begin{tabular}{|c|c|c|c|}
\hline Activity & Suggestions & Feasibility & Quotes \\
\hline $\begin{array}{l}\text { Alcohol } \\
\text { and the } \\
\text { Body }\end{array}$ & $\begin{array}{l}\text { Activity should feature how the body } \\
\text { would look after drinking alcohol. } \\
\text { Gamification and interactivity were } \\
\text { suggested (e.g. through a quiz or } \\
\text { interactive puzzle). }\end{array}$ & $\begin{array}{l}\text { Suggestions are feasible and should be brought } \\
\text { forward into a game brief. }\end{array}$ & $\begin{array}{l}\text { M, 15: "You could do it even as a game. It can } \\
\text { show how much intake and have the body parts } \\
\text { [show] how much it affects them... }\end{array}$ \\
\hline $\begin{array}{l}\text { Calorie } \\
\text { Matching } \\
\text { Activity }\end{array}$ & $\begin{array}{l}\text { As a mobile app that can be used outside of } \\
\text { the class room. Added feature suggested in } \\
\text { form of understanding how much exercise } \\
\text { it will take to burn of calories from } \\
\text { drinking alcohol. }\end{array}$ & $\begin{array}{l}\text { Developing this as a mobile app rather than an } \\
\text { online game increases the chances of a } \\
\text { prevention service outside of school hours. }\end{array}$ & $\begin{array}{l}\text { M, 14: With the new calorie match ups idea it } \\
\text { would be better to not only have the theory } \\
\text { part with it but actually tell us how much } \\
\text { exercise we have to do to get off those calories. }\end{array}$ \\
\hline $\begin{array}{l}\text { Drink } \\
\text { Victim } \\
\text { Reports }\end{array}$ & $\begin{array}{l}\text { Mostly well perceived activity that } \\
\text { students' believed to be powerful and } \\
\text { engaging. Students' suggested featuring } \\
\text { the Pledge straight after the 'victims' } \\
\text { presentation including time for discussion. }\end{array}$ & $\begin{array}{l}\text { Resourcing speakers over continued periods } \\
\text { for prevention programs is challenging (a pre- } \\
\text { recorded video may work). Featuring the } \\
\text { Pledge activity post the presentation is a good } \\
\text { strategic fit in getting students to reflect on } \\
\text { their future actions. }\end{array}$ & $\begin{array}{l}\text { M, 15: My brother's 18th. We had about } 80 \\
\text { odd people there and they had drinking games } \\
\text { and people got to a point, the angry drunks... } \\
\text { There was about five people having a full on } \\
\text { brawl and people got sent in ambulances... } \\
\text { [one person] couldn't walk ever again. It got } \\
\text { to that point. }\end{array}$ \\
\hline $\begin{array}{l}\text { Discussion } \\
\text { Session }\end{array}$ & $\begin{array}{l}\text { Students saw value in a discussion activity } \\
\text { as long as it would be engaging and } \\
\text { connected to real life events (e.g. feature } \\
\text { realistic examples). }\end{array}$ & $\begin{array}{l}\text { Discussion formats work better in smaller } \\
\text { group settings }(\mathrm{n}<25) \text { and should only then be } \\
\text { applied. Featuring a discussion session post the } \\
\text { 'drink victim’ reporting is likely to stimulate } \\
\text { debate and raise questions. }\end{array}$ & $\begin{array}{l}\text { M, 14: ...I reckon combining the drink victim } \\
\text { report with the discussion section would be } \\
\text { good because using the personal victims report } \\
\text { would give an insight into the story further } \\
\text { than probably the current affairs video. }\end{array}$ \\
\hline $\begin{array}{l}\text { Drinking } \\
\text { Mirror } \\
\text { Game }\end{array}$ & $\begin{array}{l}\text { Students' were interested in experimenting } \\
\text { with the game. There was interest in even } \\
\text { longer-term simulation effects than } \\
\text { currently featured as well as incorporating } \\
\text { the game into a photo booth experience. }\end{array}$ & $\begin{array}{l}\text { A mobile photo booth ranges between \$AUD } \\
2000 \text { - } 5000 \text { and are therefore is certainly a } \\
\text { feasible component for a next generation } \\
\text { program. }\end{array}$ & $\begin{array}{l}\text { M, 15: You could sit in it and you'd just be } \\
\text { sitting there [photo booth]. You'd take the } \\
\text { picture and then it'd come up on the screen or } \\
\text { something like that. }\end{array}$ \\
\hline
\end{tabular}


Users were willing and able to suggest a number of additional and concrete features when designing activity-based alcohol education activities, whether in the form of online games or practical activities. The inductive coding procedure identified seven reoccurring themes that emerged as part of the improvements that were suggested by the users in the co-design sessions: additional features (12), combining activities (6), realism (5), challenge (3), interactivity (2), interaction (2), and gamification (2). However, the participants primarily focused their attention on activities and games that they were most engaged with. In general this referred to activities that were closely related to or simulated reallife experiences. Improvements focused on making the activities more realistic, challenging, as well as suggesting additional features in order to improve engagement. Furthermore, a number of important suggestions were made in the co-design sessions that provided evidence for the engagement and critical reflection that vulnerable users provided during the co-design sessions.

In contrast to the positive findings, it was also observed that users faced difficulties in articulating a larger variety of and more concrete suggestions regarding activities that were less popular or not remembered well. This highlights the gap between expert-driven service design and actual user experiences and supports findings from previous studies indicating that if user engagement is not facilitated the effectiveness of such program activities is questionable (Dearing et al., 2005; Low et al., 2014). It emphasizes the importance of co-design because, as shown in this research, the suggestions provided by users particularly focused on making the activities more realistic, challenging and interactive in order to enhance engagement. Both, interactivity (Cuijpers, 2002; Foxcroft and Tsertsvadze, 2012b; Onrust et al., 2016; Tobler and Stratton, 1997) and engagement (Dearing et al., 2005; Low et al., 2014) have been established as key ingredients to designing better service offerings for vulnerable consumer groups. Therefore, co-design practices contribute to a better balance between evidence-based practice and design that is tailored to improve user experience.

These findings underline the potential benefits of co-design. Users were able to provide insights into important features and utilities that were currently missing in particular activities and which they believed to be important to increase user engagement. This is in accordance with previous research showing the importance of active user involvement to the improvement of the user value of a newly developed service (Kristensson et al., 2004; Magnusson et al. 2003). In the current study, the involvement of vulnerable consumers (i.e. adolescents) not only led to improved outcomes that might engage and motivate this group to learn about alcohol but, more importantly, enable them to make more informed decisions.

\section{Implications}

This article contributes to the service research literature by investigating how vulnerable consumers can be involved in transformative service design. Little is known about how vulnerable 
consumers can effectively be involved in the co-design of transformative services and how their involvement may contribute to improved design outcomes (Ostrom et al., 2015). The present research goes some way to addressing this knowledge gap. It reports on the insights generated from six co-design sessions that involved vulnerable consumers in the design process of a specific transformative service - an alcohol education program targeted at adolescents. As part of the preparation phase, and as reported in the method section, insights were generated in terms of how the co-design process can be planned as well as vulnerable consumers be recruited and sensitized for participation in this process. In turn, the facilitation and outcomes of the co-design sessions provided insights on the required facilitation procedures, including the use of different design tools, in order to ensure that the generated outcomes align with set objectives. The implications resulting from this research are discussed in the following sections.

\section{Theoretical implications}

Although previous research has contributed generic frameworks for active user involvement processes (Alam, 2002; Hoyer et al., 2010), including co-design (Mattelmäki and Visser, 2011; Steen et al., 2011), our findings suggest the need for an adapted framework for vulnerable consumer groups. Thus, based on the insights generated from the six co-design sessions as well as the examination of the relevant literature on user involvement and co-design, we propose a six-step framework for the involvement of vulnerable consumers in co-design processes. The six steps comprise resourcing, planning, recruiting, sensitizing, facilitation, and evaluation. This section describes each step in detail and discusses how co-design with vulnerable consumers differs from conventional user involvement processes. An overview of the key differences is provided in Table 5. 
Table 5 - A comparison of conventional and vulnerable user involvement processes

\begin{tabular}{|c|c|c|c|}
\hline Conventional user involvement process & Selected key studies & Vulnerable user involvement through co-design & Selected key studies \\
\hline \multicolumn{4}{|l|}{ Resourcing } \\
\hline - Users do the research/resourcing & & - Experts do the research/resourcing & Visser et al. (2005) \\
\hline \multicolumn{4}{|l|}{ Planning } \\
\hline \multirow{3}{*}{$\begin{array}{l}\text { - Experts plan/communicate directly with } \\
\text { users (e.g., online platforms, social } \\
\text { media) }\end{array}$} & Boudreau and Lakhani (2013) & - Experts plan/communicate with & Donetto et al. (2015) \\
\hline & Poetz and Schreier (2012) & users via intermediaries (e.g. governmental & \\
\hline & & $\begin{array}{l}\text { departments, non-profits, schools and other } \\
\text { service providers) }\end{array}$ & \\
\hline \multicolumn{4}{|l|}{ Recruiting } \\
\hline - Users self-select & Franke et al. (2006) & - Recruitment through intermediaries & Steen et al. (2011) \\
\hline - Users are driven by specific motivations & Lettl (2007) & - Incentives for participation might be required & Visser et al. (2005) \\
\hline \multicolumn{4}{|l|}{ Sensitizing } \\
\hline - Users are knowledgeable about the topic & Füller et al. (2011) & - Users need to be introduced to the topic & Mattelmäki and Visser (2011) \\
\hline $\begin{array}{l}\text { - Sensitizing through } \\
\text { challenges/competitions }\end{array}$ & Poetz and Schreier (2012) & - Trust needs to be developed with the facilitator & Steen et al. (2011) \\
\hline \multicolumn{4}{|l|}{ Facilitation } \\
\hline \multicolumn{4}{|l|}{ Evaluation } \\
\hline \multirow{3}{*}{$\begin{array}{l}\text { - Focus on service innovations that deliver } \\
\text { user value, feasibility, and originality }\end{array}$} & Magnusson (2009) & - Focus on service innovations that deliver & Cottam and Leadbeater (2004) \\
\hline & Magnusson et al. (2003) & transformation, consumer wellbeing and social & Lundkvist and Yakhlef (2004) \\
\hline & Poetz and Schreier (2012) & change & Visser et al. (2005) \\
\hline
\end{tabular}


1. Resourcing: In conventional user involvement processes this step is 'outsourced' to users through the provision of suitable innovation tools. This process, also labelled as 'democratizing innovation' (von Hippel, 2005), focuses on empowering users to take over innovation activities that were traditionally the responsibility of firm-internal experts or designers (von Hippel, 2001; Fuchs and Schreier, 2011). For example, through the provision of maker labs or innovation platforms users can innovate independently and thereby source the required information from different resources (Franke et al., 2006; Lüthje, 2004). This may not be possible when co-designing with vulnerable consumers as these users might not have either the willingness or the ability to innovate independently. They may also be sensitive to the nature of the topic and therefore more reluctant to participate. Thus, experts or researchers take on a key role during this stage by sourcing relevant inputs (e.g. program components, products/services, best practice examples) as well as reflecting on potential barriers that may hinder participation. Finally, as is shown in the present study, the resourcing stage is important to gain a better understanding of the underlying problem/task to be addressed and to develop the topic-specific design tools (e.g. activity cards) to be used in the co-design sessions.

2. Planning: During the planning stage of a user involvement process, experts typically collaborate and communicate directly with their users on matters such as organizing user meetings in innovation labs (Boudreau and Lakhani, 2013) or supporting users to independently innovate in their space (Franke et al., 2006; Lüthje, 2004). In contrast, as shown in the present research, co-design with vulnerable consumers often involves close collaboration and communication with intermediaries such as government bodies and not-for-profit organizations rather than the customer. The condition of vulnerability may preclude or render impractical direct collaboration or communication between the consumer and the expert. For example, the user group might be 'cared' for by a public institution owing to their specific vulnerability (e.g., patients in health care facilities, support service users). This implies that a number of interactions (e.g. phone and face-to-face meetings) will be required with relevant stakeholders to coordinate and agree on the methods of recruiting participants (e.g. screening methods and advertising methods) as well as receiving approvals, coordinating co-design session venues and times, and the co-design facilitation. The present study showcases this in form of lengthy negotiations in order to gain the schools' support and approval to recruit and conduct co-design sessions. This stage also involves the planning ahead for unexpected events that might occur during the co-design session (e.g., drop-out/ disengagement of participants, conflicts, off-topic discussions, etc.). Overall, the planning stage serves as an opportunity to plan the subsequent recruitment, sensitization, facilitation and evaluation stages.

3. Recruiting: Previous user involvement studies focused on identifying and recruiting innovative groups such as 'lead users', 'early adaptors', or 'market mavens' (Matthing et al., 2006; Hoyer et al., 
2010). The involvement of lead users has been shown to be particularly effective as these types of users are typically highly capable and motivated to contribute to innovation and development activities (Franke et al., 2006; Lettl, 2007). While some studies show that innovative users might be self-selecting owing to their strong motivation to innovate (e.g., innovation-related benefits, recognition, interest in innovation or the product/service) (Poetz and Schreier, 2012), others highlight the costs and time that can be involved in the recruitment process (Edvardsson et al., 2012). Differently to innovative user groups, vulnerable consumers may not have the motivation to contribute to collaborative design activities, especially in sensitive topics (e.g. alcohol education). Thus, identifying and recruiting a sufficient number of suitable users for involvement in co-design activities is likely to require close collaboration, perseverance, and the development of on-going partnerships with relevant stakeholders. The recruitment process can be lengthy and resource intensive (Visser et al., 2005), which might add to the reason why healthcare services (Donetto et al., 2015) or alcohol education programs are predominantly designed with little or no user involvement (Dietrich et al., 2016). This study highlighted the importance of tapping existing partnerships which were established through the intervention trial with key school staff members. These school staff members turned out to be an important asset in the recruitment process as they assisted in the identification and recruitment of sufficient number of participants for the co-design sessions. Thus, the recruitment phase requires the establishment and ongoing nurturing of relationships with relevant partner organizations and their staff.

4. Sensitizing: Sensitizing does not find application in the user involvement literature per se because targeted user groups typically are highly knowledgeable within the field. In fact, as shown by Magnusson et al. (2003) consulting by experts before the innovation activity can even negatively influence the generated outcomes. Yet, this stage might arguably be related to 'setting the scene' either through the definition of a specific challenge or competition (Piller and Walcher, 2006; Poetz and Schreier, 2012). For example, Füller et al. (2011) found that the experience environment is fundamental for encouraging users to explore a challenge collaboratively or contribute with new creative ideas. In the context of vulnerable user involvement, sensitizing is more concerned with the preparation of participants for the actual co-design session. Specifically, during this stage, the co-design participants should be made familiar with the requirements of the co-design session or the actual service to be redesigned (Steen et al., 2011; Visser et al., 2005). It can also inspire preliminary ideas for a new service by asking thought-evoking questions which encourage reflection. As shown in the current study, the sensitizing stage was critical for the effectiveness of co-design with vulnerable consumer groups because it allowed users to experience and test the designed activities and become familiar with the respective research context. The sensitizing stage additionally fostered user engagement and identification with the program. This may be particularly important for public service organizations and 
sensitive topics with which users do not readily identify themselves or proactively engage with (Engström and Elg, 2015).

5. Facilitation: Previous research showed that active user involvement can effectively be facilitated through competitions (Piller and Walcher, 2006; Schreier et al., 2012) or face-to-face sessions in innovation labs (Boudreau and Lakhani, 2013). This stage thereby is often user-driven and if experts are present they take on a passive consulting role (Magnusson et al., 2003). Mostly, however, conventional users design or innovate independently (Fuchs and Schreier, 2011), which may reflect their lead user status. In contrast, experts might need to take a more central role in co-design activities that involve vulnerable consumers. As shown in the present study, co-design with vulnerable consumer requires careful guidance by a trained facilitator. Such a co-design process might start with an 'icebreaker' activity to allow participants to become familiar with the facilitator and the objectives of the co-design activity. Then the focus can turn to individual activities and/or in-group discussions, followed by the development of ideas. During this stage, all co-design tools (e.g. role playing, mock-ups, cards, canvas) should be considered and selected based upon the potential to empower participants and encourage collaboration and creativity. In the present study, card sorting and collage making were found to be particularly useful to foster creativity and gain insights into the participants' preferences and beliefs about the specific games and activities they experienced during the sensitizing stage and empower them to design their preferred alcohol program. Similar to previous studies (e.g. Clatworthy, 2011; Mattelmäki and Visser, 2011), the application of topic-specific design tools, informed by the preceding resourcing stage, can empower participants and facilitate collaboration and creativity during the design process.

6. Evaluation: User generated ideas or innovations are typically evaluated in terms of innovation outcomes, including originality, feasibility, and user value (Magnusson et al., 2003; Poetz and Schreier, 2012; Witell et al., 2011). A key focus thereby is on identifying radical new ideas that are valuable for the firm's innovation process (Magnusson, 2009; Poetz and Schreier, 2012). Co-design processes involving vulnerable consumers are likely to follow different outcome objectives, such as transformation and improving consumer wellbeing. As experts of their experiences, users may be an important contributor to transformative service design and the improvement of wellbeing (Cottam and Leadbeater, 2004; Lundkvist and Yakhlef, 2004). Although evaluation is important for all user involvement activities, it is particularly so in the context of vulnerable consumers given the dearth of previous research in this area and the participation of users who are likely to differ in their motivation and ability to contribute to these activities (Engström and Elg, 2015). If executed poorly, involvement of vulnerable users may lead to costly new service failures (cf. Ostrom et al., 2015). The co-design outcomes generated by the participants in the current study led to improvements in game and activity 
design, new combinations of existing activities, and even new design ideas. Overall, the participants contributed unique knowledge about their needs and preferences, which subsequently informed the design of the updated alcohol education program's activities. Thereby, feasibility was gauged by the research team with regards to cost and time to market. The present study also showed that vulnerable consumers had difficulty to remember and therefore contribute to activities that they were less engaged with. This creates an additional challenge to the overall outcomes and success of co-design activities as users might not be able to provide meaningful feedback and ideas for improvement if they are not engaged in the activity in the first place. Still, the findings of this study will assist in further narrowing the gap between the current service design (i.e. alcohol education program) and the user's wants and needs to foster more engagement and ultimately consumer wellbeing.

\section{Practical implications}

This study provides a guide on how co-design activities with vulnerable consumers can be effectively resourced, planned, recruited, sensitized, facilitated, and evaluated for transformative service design. The six-step framework identifies important differences that need to be considered by organizations seeking to involve vulnerable consumer groups through co-design. Apart from the more expert-driven and resource-intensive nature of the resourcing, planning, recruiting, and facilitation stages, the sensitizing of participants before the co-design facilitation stage may be critical to co-design success. Empowering participants to clearly define their preferences and encouraging and motivating them to share their 'voice' can be very challenging when working with vulnerable consumers (Ringold, 2005; Spotswood and Nairn, 2016). As shown in the current study, the co-design facilitation combined with the preceding sensitizing stage did provide a better understanding of user experiences and preferences and encouraged users to take ownership in improving the expert-designed program. This is an important aspect because, as emphasized by Junginger (2009), the aim of service design is not only to improve the service provision per se but also to have a transformational impact by creating collaborative service models that work for people "outside” and "inside”, thus bringing perspectives and experiences of "other people" into the organization through the practices of designing. While oneoff co-design sessions may have limited substantial transformational impact, such sessions serve as an important starting point for uncovering and questioning traditional expert views and assumptions on service production and delivery (Sangiorgi, 2011), thus closing the gap between expert-design and user wants and needs.

Further, during the facilitation stage the card sorting activity proved to be a beneficial tool to engage adolescents and was particularly useful for optimizing the short timeframe that was available to the facilitator (Clatworthy, 2011). It allowed the facilitator to gain input from each participant, encouraged in-group discussions, and effectively empowered the vulnerable consumer group. This is an important finding as Cottam and Leadbeater (2004) suggest that the most underexplored and 
untapped resource in health care are the users. The application of cards may also be of particular importance for co-design because, as noted by Lundkvist and Yakhlef (2004), ideas do not exist in abstractum but take shape in and through conversational engagement between users and designers. Understanding that users are in fact experts of their very own experiences and can therefore significantly contribute to improved service design may offer a direct means to enhance wellbeing.

Lastly, it might be difficult for untrained designers or researchers to successfully facilitate codesign processes with vulnerable user groups. Successful co-design facilitation requires certain skills including the development of a trusting environment between the involved users and the experts, providing users with guidance during their participation, and engaging and empowering each individual to contribute and share his or her experiences (Sangiorgi, 2011). This finding implies that co-design is not something that anyone can facilitate, even if the appropriate design tools are applied. Using a toolbox metaphor, Blomkvist and Segelström (2015) highlighted: “one has to fill one’s tool-box with various tools, but just having a full toolbox does not make someone into a craftsman”. It is just as important to learn which tool to use for which purpose and to be able to find new solutions when the existing tools are not enough.” This argument has been supported in the current study as the researchers needed to facilitate a trusting environment to allow participants to openly share their experiences, carefully encourage quiet participants to voice their opinions, and trigger ongoing initiatives by allowing users to take ownership of the program (cf. Manzini and Rizzo, 2011). Thus, the application of appropriate design tools is unlikely to be sufficient, but rather should be seen as a supportive element of co-exploring and co-designing (Clatworthy, 2011; Mattelmäki et al., 2011).

\section{Limitations and future research}

Despite its contributions, this research has limitations. The study took an early step in proposing a six-step framework that identifies how the involvement of vulnerable consumer groups through codesign differs from conventional user involvement processes. For practice, the framework provides guidance for successfully facilitating co-design sessions with vulnerable consumers. We see merit in the co-design framework for a) striking a better balance between evidence-based practice and activity designs that are more appealing and engaging to vulnerable consumers and b) contribute to further improving existing services to enhance their experience and engagement. Nevertheless, given the qualitative nature of the study it is important to acknowledge that while our co-design framework worked well within the vulnerable adolescent group examined by the research, its generalizability is currently limited to the context of this study (Maxwell, 1992; Johnson, 1997). However, given its strong foundation in the co-design literature (Donetto et al., 2015; Mattelmäki and Visser, 2011; Manzini and Rizzo, 2011; Steen et al. 2011; Visser et al., 2005), the proposed six-step framework and utilized tools in this study may be useful for involvement of other vulnerable consumer groups to gain insights to 
inform the design of other transformative services such as health and financial services. Further empirical testing is required and warranted.

This study was restricted to six private, religiously-denominated (Catholic) schools in one state of Australia that had participated in the GOKA program. The sample included urban and regional schools. It is important to note that past research shows no association between socio-economic status and alcohol consumption in adolescence (e.g. Tuinstra et al., 1998), although more recent research suggests that adolescents from affluent backgrounds drink even more alcohol (e.g. Pedersen et al., 2015). Similarly, the results surrounding religious influence on drinking is complex (see Brown et al., 2001) and it is important not to assume that the adolescents in the study subscribe to the religious beliefs of their school. Although beyond the scope of the current study, future research should examine the codesign framework and its utilized tools in service design of other school-based programs as well as other transformative services to further improve its generalizability.

Finally, we recommend comparing the card sorting to other co-design techniques (e.g. 2D collages, diaries, acting, games and props) to understand whether the co-design technique used impacts the design outcome. It would be interesting to investigate the suitability of the card sorting method in co-design sessions when taking into account vulnerable consumers' participation styles. Engström and Elg (2015) identified a number of styles, such as playful or social, of participation in service design which may influence the usefulness of a card sorting approach. It will also be important to investigate the application of different co-design tools to different contexts and populations of vulnerable consumers (e.g. mentally ill, elderly, etc.).

\section{In summary}

Service design for vulnerable consumers has been identified as a key priority to advance and benefit the service field (Ostrom et al., 2015). This research contributed to this priority by investigating how vulnerable consumers can be involved in the co-design of transformative services aiming to improve consumer wellbeing. A fundamental principle of co-design is ensuring that (vulnerable) consumers are empowered to contribute to the design process (Mattelmäki, 2008), which is important given that consumer empowerment is vital to addressing consumer vulnerability (Baker et al., 2005). Despite this, current user involvement frameworks do not account for the unique characteristics of vulnerable consumer groups that may influence the efficacy of this approach to service design.

To address this gap, the present research investigated how one vulnerable group, namely adolescents, could be involved in the co-design of an alcohol education program. A comparison to conventional user involvement processes, led to the identification of important differences that need to be considered by both researchers and practitioners when vulnerable consumers are to be involved through co-design. As a result of this investigation, a six-step co-design framework comprising resourcing, planning, recruiting, sensitizing, facilitation, and evaluation for the involvement of 
vulnerable consumer groups in co-design was proposed. The research further showed that the involvement of vulnerable consumers can contribute to important improvements to transformative services and, as such, has the potential to reduce the gap between expert-design and user needs and contribute to improved wellbeing benefits. This research provides an important basis for research and practice in the nascent, but growing field examining the intersection of transformative services and vulnerable consumers. 


\section{References}

AIHW (2014), National Drug Strategy Household Survey detailed report 2013, Drug statistics series no. 28, Cat. no. PHE 183, pp. 1-151, Canberra, Australia.

Alam, I. (2002), "An exploratory investigation of user involvement in new service development", Journal of the Academy of Marketing Science, Vol. 30 No. 3, pp. 250-261.

Alcolado, R. and Alcolado, J. (2011), "Medical student delivery of alcohol education to high school pupils: the MEDALC programme", Clinical Medicine (London, England), Vol. 11 No. 5, pp. 443-447.

Anderson, L., Ostrom, A., Corus, C., Fisk, R., Gallan, A., Giraldo, M., . . Williams, J. (2013), "Transformative service research: an agenda for the future", Journal of Business Research, Vol. 66, pp. 1203-1210.

Baker, S. Gentry, J. and Rittenburg, T. (2005), "Building understanding of the domain of consumer vulnerability", Journal of Macromarketing, Vol. 25 No. 2, pp. 128-139.

Bentley, T. and Wilsdon, J. (2003), The Adaptive State: Strategies for Personalising the Public Realm, Demos, London.

Berry, L. and Bendapudi, N. (2007), "Health care a fertile field for service research", Journal of Service Research, Vol. 10 No. 2, pp. 111-122.

Blomkvist, J. and Segelström, F. (2015), "Benefits of external representations in service design: a distributed cognition perspective", The Design Journal, Vol. 17 No. 3, pp. 331-346.

Boudreau, K.J. and Lakhani, K.R. (2013), "Using the crowd as an innovation partner", Harvard Business Review, Vol. 91 No. 4, pp. 60-69.

Brandt, E., Messeter, J. and Binder, T. (2008), "Formatting design dialogues-games and participation", Co-Design, Vol. 4 No. 1, pp. 51-64.

Brown, T. L., Parks, G. S., Zimmerman, R. S. and Phillips, C. M. (2001), The role of religion in predicting adolescent alcohol use and problem drinking, Journal of Studies on Alcohol, Vol. 62 No. 5, pp. 696-705.

Chris, V., Tsikriktsis, N., \& Frohlich, M. (2002), Case research in operations management, International Journal of Operations \& Production Management, Vol. 22 No. 2, pp. 195-219.

Clatworthy, S. (2011), "Service innovation through touch-points: Development of an innovation toolkit for the first stages of new service development", International Journal of Design, Vol. 5 No. 2, pp. 15-28.

Cornwall, A. (2008), Democratising Engagement: What the UK can Learn from International Experience, Demos, London.

Corus, C. and Saatcioglu, B. (2015), "An intersectionality framework for transformative services research", The Service Industries Journal, Vol. 35 No. 7-8, pp. 415-429. 
Cottam, H. and Leadbeater, C. (2004), Red Paper 01: Health: Co-creating Services, Design Council, London.

Cuijpers, P. (2002), "Effective ingredients of school-based drug prevention programs: A systematic review", Addictive Behaviors, Vol. 27 No. 6, pp. 1009-1023.

Dearing, R., Barrick, C., Dermen, K. and Walitzer, K. (2005), "Indicators of client engagement: influences on alcohol treatment satisfaction and outcomes", Psychology of Addictive Behaviors, Vol. 19 No. 1, pp. 71-80.

Dietrich, T., Rundle-Thiele, S., Schuster, L. and Connor, J. (2016), "A systematic literature review of alcohol education programmes in middle and high school settings (2000-2014)", Health Education, Vol. 116 No. 1, pp. 50-68.

Dietrich, T., Rundle-Thiele, S., Schuster, L. and Connor, J. (2016),"Co-designing social marketing programs", Journal of Social Marketing, Vol. 6 No. 1, pp. 41-61.

Donetto, S., Pierri, P., Tsianakas, V. and Robert, G. (2015), "Experience-based co-design and healthcare improvement: Realizing participatory design in the public sector", The Design Journal, Vol. 18 No. 2, pp. 227-248.

Edvardsson, B., Kristensson, P., Magnusson, P. and Sundström, E. (2012), "Customer integration within service development-A review of methods and an analysis of insitu and exsitu contributions", Technovation, Vol. 32 No. 7, pp. 419-429.

Edvardsson, B., Meiren, T., Schäfer, A. and Witell, L. (2013), "Having a strategy for new service development - Does it really matter?", Journal of Service Management, Vol. 24 No. 1, pp. 2544.

Engström, J. and Elg, M. (2015), "A self-determination theory perspective on customer participation in service development", Journal of Services Marketing, Vol. 29 No. 6/7, pp. 511-521.

Evenson, S. (Ed.). (2008), A Designer's View of SSME, Springer, New York.

Foxcroft, D. and Tsertsvadze, A. (2012a), "Universal alcohol misuse prevention programmes for children and adolescents: Cochrane systematic reviews", Perspectives in Public Health, Vol. 132 No. 3, pp. 128-134.

Foxcroft, D. and Tsertsvadze, A. (2012b), "Universal school-based prevention programs for alcohol misuse in young people (Review)", Evid.-Based Child Health, Vol. 7 No. 2, pp. 450-575.

Franke, N., von Hippel, E. and Schreier, M. (2006), "Finding commercially attractive user innovations: A test of lead-user theory", Journal of Product Innovation Management, Vol. 23 No. 4, pp. 301-315.

Fry, M. L. (2010), Countering consumption in a culture of intoxication, Journal of Marketing Management, Vo. 26 No. 13-14, pp. 1279-1294.

Fuchs, C. and Schreier, M. (2011), "Customer empowerment in new product development", Journal of Product Innovation Management, Vol. 28 No. 1, pp. 17-32. 
Füller, J., Hutter, K. and Faullant, R. (2011), "Why co-creation experience matters? Creative experience and its impact on the quantity and quality of creative contributions", R\&D Management, Vol. 41 No. 3, pp. 259-273.

Gemser, G. and Perks, H. (2015), "Co-creation with customers: An evolving innovation research field", Journal of Product Innovation Management, Vol. 32 No. 5, pp. 660-665.

Guo, L., Arnould, E., Gruen, T. and Tang, C. (2013), "Socializing to co-produce: Pathways to consumers' financial well-being", Journal of Service Research, Vol. 16 No. 4, pp. 549-563.

Hardoff, D., Stoffman, N. and Ziv, A. (2013), "Empowering adolescents to control alcohol-associated risky situations", Archives of Disease in Childhood, Vol. 98 No. 9, pp. 672-675.

Holmlid, S. (2007), "Interaction design and service design: expanding a comparison of design disciplines", available at http://www.ida.liu.se/divisions/hcs/ixs/material/servicedesignGbg10/0\%20On\%20service\%20 design/Interaction\%20vs\%20Service.pdf

Holmlid, S. and Evenson, S. (2008), "Bringing service design to service sciences, management and engineering", in Service Science, Management and Engineering Education for the 21st Century, Springer, pp. 341-345.

Johnson, R. (1997), Examining the validity structure of qualitative research, Education, Vol. 118, pp. 282.

Holmlid, S. (2009), "Participative, co-operative, emancipatory: from participatory design to service design", available at: http://www.aho.no/en/AHO/News-and-events/ServiceDesign/Program1/PapersAbstracts/

Junginger, S. (2009), "Designing from the outside in: the key to organizational change", paper presented at the Conference Proceedings of the 8th Conference of the European Academy of Design, Aberdeen, Scotland.

Kimbell, L. (2011), "Designing for service as one way of designing services", International Journal of Design, Vol. 5 No. 2, pp. 41-52.

Krippendorff, K. (2006), The Semantic Turn: A new Foundation for Design, Taylor \& Francis, Boca Raton.

Krippendorff, K. (2011), "Principles of design and a trajectory of artificiality", Journal of Product Innovation Management, Vol. 28 No. 3, pp. 411-418.

Kristensson, P., Gustafsson, A. and Archer, T. (2004), "Harnessing the creative potential among users", Journal of Product Innovation Management, Vol. 21 No. 1, pp. 4-14.

Lettl, C. (2007), "User involvement competence for radical innovation", Journal of Engineering and Technology Management, Vol. 24 No. 1/2, pp. 53-75. 
Low, S., Van Ryzin, M., Brown, E., Smith, B. and Haggerty, K. (2014), "Engagement matters: Lessons from assessing classroom implementation of steps to respect: a bullying prevention program over a one-year period", Prevention Science, Vol. 15 No. 2, pp. 165-176.

Lundkvist, A. and Yakhlef, A. (2004), "Customer involvement in new service development: A conversational approach", Managing Service Quality, Vol. 14 No. 2/3, pp. 249-257.

Lüthje, C. (2004), "Characteristics of innovating users in a consumer goods field: An empirical study of sport-related product consumers", Technovation, Vol. 24 No. 9, pp. 683-695.

Maglio, P. P. and Spohrer, J. (2008), "Fundamentals of service science", Journal of the Academy of Marketing Science, Vol. 36 No. 1, pp. 18-20.

Magnusson, P.R., Matthing, J. and Kristensson, P. (2003), "Managing user involvement in service innovation", Journal of Service Research, Vol. 6 No. 2, pp. 111-124

Magnusson, P.R. (2009), "Exploring the contributions of involving ordinary users in ideation of technology-based services", Journal of Product Innovation Management, Vol. 26 No. 5, pp. 578-593.

Manzini, E. and Rizzo, F. (2011), "Small projects/large changes: Participatory design as an open participated process", CoDesign, Vol. 7 No. 3-4, pp. 199-215.

Matthing, J., Kristensson, P., Gustafsson, A. and Parasuraman, A. (2006), "Developing successful technology-based services: The issue of identifying and involving innovative users", Journal of Service Marketing, Vol. 20 No. 5, pp. 288-297.

Mattelmäki, T. (2008), "Probing for co-exploring", Co-Design, Vol. 4, No. 1, pp. 65-78.

Mattelmäki, T., Brandt, E. and Vaajakallio, K. (2011), "On designing open-ended interpretations for collaborative design exploration", CoDesign, Vol. 7 No. 2, pp. 79-93.

Mattelmäki, T. and Visser, F.S. (2011), "Lost in Co-X: Interpretations of co-design and co-creation", paper presented at the Diversity and Unity, Proceedings of IASDR2011, the 4th World Conference on Design Research, Delft, Netherlands.

Maxwell, JA (1992), Understanding Validity in Qualitative Research, Harvard Educational Review, Vol. 62 No. 3, pp. 279-300.

McBride, N., Farringdon, F., Midford, R., Meuleners, L. and Phillips, M. (2004), "Harm minimization in school drug education: final results of the School Health and Alcohol Harm Reduction Project (SHAHRP)", Addiction, Vol. 99 No. 3, pp. 278-291.

McCambridge, J., McAlaney, J. and Rowe, R. (2011), "Adult consequences of late adolescent alcohol consumption: a systematic review of cohort studies", PLoS medicine, Vol. 8 No. 2, pp. 1-13.

McColl-Kennedy, J. R., Vargo, S. L., Dagger, T. S., Sweeney, J. C. and van Kasteren, Y. (2012), "Health care customer value cocreation practice styles", Journal of Service Research, Vol. 15 No. 4, pp. 370-389.

Meroni, A. and Sangiorgi, D. (2011), Design for Services, Gower Publishing, Surrey. 
Merriam, S. (1998), Qualitative Research and Case Study Applications in Education. Revised and Expanded from "Case Study Research in Education", Jossey-Bass Publishers, San Francisco, CA.

Nurmuliani, N., Zowghi, D. and Williams, S. (2004), "Using card sorting technique to classify requirements change", paper presented at the Requirements Engineering Conference, Proceedings, 12th IEEE International.

Onrust, S., Otten, R., Lammers, J., \& Smit, F. (2016). School-based programmes to reduce and prevent substance use in different age groups: What works for whom? Systematic review and meta-regression analysis. Clinical Psychology Review, Vol. 44, pp. 45-59.

Osei-Frimpong, K., Wilson, A., \& Owusu-Frimpong, N. (2015). Service experiences and dyadic value co-creation in healthcare service delivery: A CIT approach. Journal of Service Theory and Practice, Vol. 25 No. 4, pp. 443-462.

Ostrom, A.L., Bitner, M.J., Brown, S.W., Burkhard, K.A., Goul, M., Smith-Daniels, V., Demirkan, H. and Rabinovich, E. (2010), "Moving forward and making a difference: Research priorities for the science of service", Journal of Service Research, Vol. 13 No. 1, pp. 4-36.

Ostrom, A. L., Parasuraman, A., Bowen, D. E., Patrício, L. and Voss, C. A. (2015), "Service research priorities in a rapidly changing context", Journal of Service Research, Vol. 18 No. 2, pp. 127159.

Palmer, J., Duffy, T., Gomoll, K., Gomoll, T., Richards-Palmquist, J. and Trumble, J. (1988), "The design and evaluation of online help for Unix EMACS: capturing the user in menu design", Professional Communication, IEEE Transactions on, Vol. 31 No. 1, pp. 44-51.

Pedersen, W., Bakken, A., \& Soest, T. (2015), "Adolescents from affluent city districts drink more alcohol than others", Addiction, Vol. 110 No. 10, pp. 1595-1604.

Piaget, J. (1952), The Origins of Intelligence in Children, New York: International University Press.

Piller, F.T. and Walcher, D. (2006), "Toolkits for idea competitions: A novel method to integrate users in new product development", $R \& D$ Management, Vol. 36 No. 3, pp. 307-318.

Patrício, L., Fisk, R. P., Falcão e Cunha, J. and Constantine, L. (2011), "Multilevel service design: from customer value constellation to service experience blueprinting", Journal of Service Research, Vol. 14 No. 2, pp. 180-200.

Pinho, N., Beirão, G., Patrício, L. and Fisk, R. (2014), "Understanding value co-creation in complex services with many actors", Journal of Service Management, Vol. 25 No. 4, pp. 470-493.

Pazart, L., Vidal, C., Chalon, D., Gauthier, S., Schepens, F., Cretin, E., Beal, J.L., Pfitzenmeyer, P., Aubry, R. (2011), "Card sorting: a tool for research in ethics on treatment decision-making at the end of life in Alzheimer patients with a life threatening complication", BMC Palliative Care, Vol. 10 No. 4, pp. 1-6.

Poetz, M.K. and Schreier, M. (2012), "The value of crowdsourcing: can users really compete with 
professionals in generating new product ideas?", Journal of Product Innovation Management, Vol. 29 No. 2, pp. 245-256.

Ranaweera, C., \& Sigala, M. (2015). "From service quality to service theory and practice", Journal of Service Theory and Practice, Vol. 25 No. 1, pp. 2-9.

Randolph, K., Archuleta, A., Smith, T. and Teasley, M. (2013), "Beliefs about alcohol use among youths during early adolescence", Journal of Child \& Adolescent Substance Abuse, Vol. 22 No. 4, pp. 295-320.

Ringold, D. (2005), "Vulnerability in the Marketplace: Concepts, Caveats, and Possible Solutions", Journal of Macromarketing, Vol. 25 No. 2, pp. 202-214.

Rosenbaum, M., Corus, C., Ostrom, A., Anderson, L., Fisk, R., Gallan, A., . . Williams, J. (2011), "Conceptualisation and aspiration of transformative service research", Journal of Research for Consumers, Vol. 19, pp. 1-6.

Rosenbaum, M., Sweeney, J. and Smallwood, J. (2011), "Restorative cancer resource center servicescapes", Managing Service Quality: An International Journal, Vol. 21 No. 6, pp. 599616.

Rosenbaum, M., Sweeney, J. and Massiah, C. (2014), "The restorative potential of senior centers", Managing Service Quality: An International Journal, Vol. 24 No. 4, pp. 363-383.

Rosenbaum, M. (2015), "Transformative service research: research that matters", The Service Industries Journal, Vol. 35 No. 15-16, pp. 801-805.

Rundle-Thiele, S., Russell-Bennett, R., Leo, C., \& Dietrich, T. (2013), "Moderating teen drinking: combining social marketing and education", Health Education, Vol. 113 No. 5, pp. 392-406.

Rundle-Thiele, S., Schuster, L., Dietrich, T., Drennan, J., Russell-Bennett, R., Leo, C., \& Connor, J. (2015). "Maintaining or Changing a Drinking Behavior? GOKA’s Short-term Outcomes", Journal of Business Research, Vol. 68 No. 10, pp. 2155-2163.

Sanders, E. B. and Dandavate, U. (1999), "Design for experiencing: New tools", paper presented at the Proceedings of the First International Conference on Design and Emotion, Delft, Netherlands.

Sanders, E. B. and Stappers, P. J. (2008), "Co-creation and the new landscapes of design", CoDesign, Vol. 4 No. 1, pp. 5-18.

Sanders, E. B., Brandt, E. and Binder, T. (2010), "A framework for organizing the tools and techniques of participatory design", paper presented at the Participatory Design Conference, Australia, Sydney.

Sanders, E.B.-N. and Westerlund, B., (2011), "Experiencing, exploring and experimenting in and with co-design spaces", Nordes, Helsinki.

Sangiorgi, D. (2011), "Transformative services and transformation design", International Journal of Design, Vol. 5 No. 2, pp. 29-40. 
Sangiorgi, D. and Junginger, S. (2015), "Emerging issues in service design", The Design Journal, Vol. 18 No. 2, pp. 165-170.

Schuster, L., Drennan, J. and Lings, I. (2013), "Consumer acceptance of m-wellbeing services: a social marketing perspective", European Journal of Marketing, Vol. 47 No. 9, pp. 1439-1457.

Schuster, L., Drennan, J. and Lings, I. (2015), "Understanding consumers’ decisions to adopt technology-enabled transformative services", The Service Industries Journal, Vol. 35 No. 15/16, pp. 846-864.

Siqueira, L., Smith, V., \& Committee on Substance Abuse (2015), "Binge drinking", Pediatrics, Vol. 136 No. 3, pp. 718-726.

Spotswood, F., \& Nairn, A. (2016), "Children as vulnerable consumers: a first conceptualisation", Journal of Marketing Management, No. 32 Vol. 3-4, pp. 211-229.

Steen, M., Manschot, M., \& Koning, N. (2011), "Benefits of Co-design in Service Design Projects", International Journal of Design, No. 5 Vol. 2, pp. 53-60.

Szmigin, I., Bengry-Howell, A., Griffin, C., Hackley, C. and Mistral, W. (2011), "Social marketing, individual responsibilty and the culture of intoxication", European Journal of Marketing, Vol. 45 No. 5, pp. 759-779.

Thomas, D. (2006), "A general inductive approach for analyzing qualitative evaluation data", American Journal of Evaluation, Vol. 27, pp. 237-246.

Tobler, N. and Stratton, H. (1997), "Effectiveness of school-based drug prevention programs: a metaanalysis of the research", The Journal of Primary Prevention, Vol. 18 No. 1, pp. 71-128.

Tuinstra, J., Groothoff, J. W., Van Den Heuvel, W. J., and Post, D. (1998), "Socio-economic differences in health risk behavior in adolescence: Do they exist?", Social Science \& Medicine, Vol. 47 No. 1, pp. 67-74.

Upchurch, L., Rugg, G. and Kitchenham, B. (2001), "Using card sorts to elicit web page quality attributes", Software, IEEE, Vol. 18 No. 4, pp. 84-89.

Vargo, S. L. and Lusch, R. F. (2008), "Service-dominant logic: continuing the evolution", Journal of the Academy of Marketing Science, Vol. 36 No. 1, pp. 1-10.

Vaughn, S., Schumm, J. and Sinagub, J. (1996), Focus Group Interviews in Education and Psychology, Sage Publications.

Visser, F. S., Stappers, P. J., Van der Lugt, R. and Sanders, E. B. (2005), "Contextmapping: experiences from practice", CoDesign, Vol. 1 No. 2, pp. 119-149.

von Hippel, E. (2001), "User toolkits for innovation", Journal of Product Innovation Management, Vol. 18 No. 4, pp. 247-257.

von Hippel, E. (2005), Democratizing innovation, The MIT Press, Cambridge.

Voss, C., Tsikriktsis, N. and Frohlich, M. (2002), "Case Research in Operations Management", International Journal of Operations \& Production Management, Vol. 22 No. 2, pp. 195-219. 
Wetter-Edman, K., Sangiorgi, D., Edvardsson, B., Holmlid, S., Grönroos, C. and Mattelmäki, T. (2014), "Design for value co-creation: exploring synergies between design for service and service logic", Service Science, Vol. 6 No. 2, pp. 106-121.

Will, K. and Sabo, C. (2010), "Reinforcing Alcohol Prevention (RAP) Program: a secondary school curriculum to combat underage drinking and impaired driving", Journal of Alcohol and Drug Education, Vol. 54 No. 1, pp. 14 -36.

Witell, L., Kristensson, P., Gustafsson, A. and Löfgren, M. (2011), "Idea generation: customer cocreation versus traditional market research techniques", Journal of Service Management, Vol. 22 No. 2, pp. 140-159.

Wunderlich, P., Kranz, J., Totzek, D., Veit, D., \& Picot, A. (2013), "The Impact of Endogenous Motivations on Adoption of IT-Enabled Services The Case of Transformative Services in the Energy Sector", Journal of Service Research, Vol. 16 No. 3, pp. 356-371.

Zimmerman, D. and Akerelrea, C. (2002), "A group card sorting methodology for developing informational web sites", paper presented at the Professional Communication Conference, IPCC 2002, Proceedings, IEEE International. 